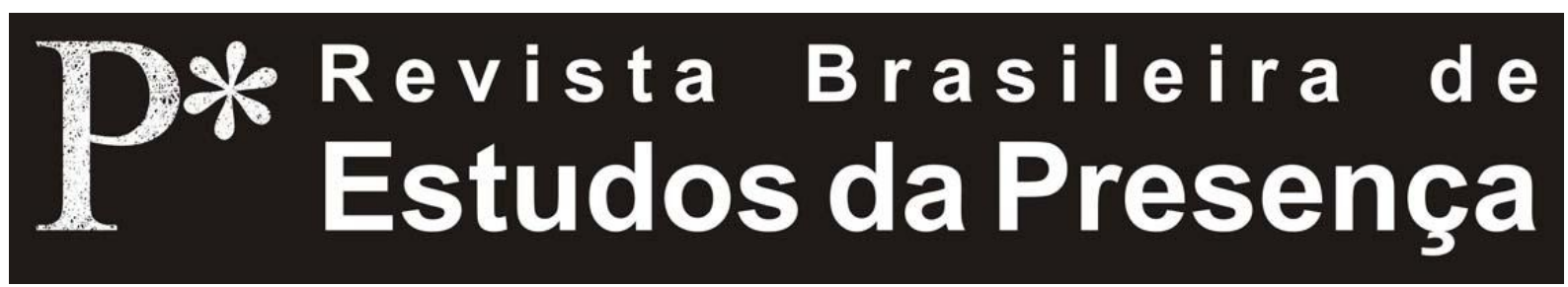

DOI - http://dx.doi.org/10.1590/2237-266021792

ISSN 2237-2660

\title{
Presença e Processos de Subjetivação
}

\author{
Beatriz Ângela Vieira Cabral \\ Universidade do Estado de Santa Catarina - UDESC
}

RESUMO - Presença e Processos de Subjetivação - Este artigo apresenta uma reflexão sobre uma perspectiva pedagógica para intensificar a presença do aluno/ator em representações e práticas performativas. Para tanto, considera pressupostos de processos de subjetivação relacionados com a materialidade (suporte material) e imaterialidade (carga informacional e emocional) de trabalhos de criação. A abordagem é exemplificada através de procedimentos pedagógicos utilizados com a estratégia do estímulo composto no campo do process drama.

Palavras-chave: Presença. Processos de Subjetivação. Materialidade e Imaterialidade. Composição de Estímulos. Process Drama.

\begin{abstract}
Presence and Subjectivation Processes This article presents a reflection on an educational perspective to enhance the presence of the student/actor at theatre representations and performances. To carry out this task it considers the subjectivation processes related to materiality (material support) and immateriality (emotional and informational load) of the creative work. The approach is exemplified by pedagogical procedures based on the strategy of the compounding stimulus in the area of process drama.

Keywords: Presence. Subjectivation Processes. Materiality and Immateriality. Compounding Stimulus. Process Drama.

RÉSUMÉ - Présence et Processus de Subjectivation - Cet article présente une réflexion sur une perspective éducative pour améliorer la présence de l'étudiant/acteur du spectacle dans les
\end{abstract}

Beatriz Ângela Vieira Cabral, Presença e Processos de Subjetivação

R.bras.est.pres., Porto Alegre, v.1, n.1, p. 107-120, jan./jun., 2011.

Disponível em http://www.seer.ufrgs.br/presenca 
représentations et les pratiques performatif. D'examiner les deux hypothèses de processus subjectivante liés à la matérialité (support matériel) et immatérialité (charge informationnelle et émotionnelle) du travail de création. L'approche est illustrée par des procédures pédagogiques de le stratégie stimulus composé dans le domaine du théâtre processus.

Mots-clés: Présence. Processus Subjectivante. Matérialité et Immatérialité. Stimulus Composé. Process Drama.

A presença, em cena, na sala de aula, na esfera social, é espaço de afetos que contaminam e subvertem a identidade do indivíduo - este se percebe ou é percebido de acordo com as variações e intensidade de seus afetos.

Em que medida esta percepção de si se associa à percepção que o sujeito tem do contexto e das circunstâncias em foco (a percepção de seus afetos) e à noção de presença no jargão teatral, que, segundo Patrice Pavis (2003, p. 305), se associa ao "[...] saber cativar a atenção do público e impor-se"? Ou, à noção de presença no campo da pedagogia do teatro, que corresponde ao engajamento físico e emocional do aluno/ator? Não estariam estes entendimentos associados à intensidade dos afetos?

Ao questionar as práticas de formação, Jean-Pierre Ryngaert (2009) aponta para a experiência insubstituível dos atores em contato com o jogo, no interior da representação - um espaço de criação onde as formas experimentadas estão ligadas às razões profundas da presença dos jogadores. Para Ryngaert, a relação do teatro com a ficção leva a uma reflexão sobre a interioridade do sujeito e sua expressão, sobre a manifestação de emoções e sensações, que vai além de uma oposição estrita entre processo e produto.

Yi-Fu Tuan chama a atenção para o termo experiência, lembrando como ele cobre os vários modos através dos quais uma pessoa conhece e constrói uma realidade - estes abrangem desde os sentidos mais diretos e passivos de cheiro, gosto e toque, à percepção visual ativa e o modo indireto de simbolização. Para Tuan, a experiência é dirigida ao mundo externo; ser e pensar vão além do eu; segundo Ricoeur, 
[...] o sentimento é sem dúvida intencional: é um sentimento de alguma coisa [...] mas é uma intencionalidade muito estranha, que por um lado designa as qualidades sentidas sobre coisas, sobre pessoas, sobre o mundo, e por outro lado, manifesta e revela a forma pelo qual o 'eu' é internamente afetado. No sentimento uma intenção e um afeto coincidem em uma mesma experiência (apud Tuan, 2008, p. 8-9).

Intenção e afeto estariam assim na base da presença. $\mathrm{O}$ entendimento de que existe uma correspondência entre ter presença e estar presente, quer na representação ou em práticas performativas, é o ponto de partida para esta reflexão sobre uma perspectiva pedagógica para a intensificação da presença em práticas de ensino. Neste sentido, são considerados os pressupostos de experiência subjetiva na sua relação com a materialidade e a imaterialidade do processo de criação, e incluída (e comentada) uma possibilidade de processo de subjetivação no campo do dramal, a qual propõe ações e gera motivações que levam o aluno/ator a objetivar intenções e intensificar afetos no percurso de experiências em teatro.

\section{A Experiência do Sujeito - materialidade e imaterialidade do processo criativo}

A presença, como uma experiência subjetiva, e o estar presente como resultante de um processo de subjetivação, relacionam o sentimento de si, a fluência entre atenção e estímulos do contexto (do público, das interações em cena) e entre atenção e estímulo das informações (desafios do texto, da identificação com o outro e com a situação em foco). Neste sentido, ambos se constituem a chave para a criação teatral, e estão vinculados aos processos pedagógicos de formação do ator e do professor. Sentir-se presente está associado com disponibilidade para a ação e com motivações pessoais para criar, apresentar, apreciar.

A intensidade do envolvimento do aluno/ator com a materialidade (suporte material) e a imaterialidade (potencial expressivo do suporte) da cena tem sido vista quer como energia decorrente de um treinamento físico intenso, quer como impacto gerado pela carga emocional 
do suporte. A distinção entre as duas posturas parece questionar se é a rotina exaustiva de ações físicas que gera um estado de jogo ou se é o espírito do texto que instaura um corpo que responde ao jogo do texto e da cena. Em outras palavras, a presença está associada à disciplina do ator, ou à carga informacional e emocional do suporte?

Em experiências teatrais em grupo, o enquadramento, o ponto de vista, ou a perspectiva compartilhada (as nomenclaturas diferem, mas se referem à mesma função) funciona como um fator de intersubjetividade - o grupo partilha o mesmo olhar, o mesmo espaço e o mesmo tempo; como afirma Couchot ao se referir à fotografia, "[...] o Nós dá acesso ao Eu" (2003, p. 29). O que permite este compartilhar que dá acesso ao pessoal e subjetivo, segundo Couchot (2003, p. 311), é a dimensão singular do sensorial na arte, que resulta tanto de sua materialidade, quanto de sua imaterialidade, sem a qual não poderia captar o olhar, a escuta e a atenção.

Ao propor uma pedagogia relacional do pensar e do sonhar, Gaston Bachelard se reporta à matéria como um grupo de ressonâncias, onde a pluralidade no nível da imaginação e no nível do epistemológico questiona o processo do conhecimento - os estatutos da objetividade e da subjetividade - afirmando que o homem se define por ambos. É neste sentido, que Deleuze e Guattari, na trilha de Bergson, veem o virtual como um modo de realidade aberto a mudanças, que não está contido em qualquer forma atual; que simplesmente trafega de uma forma a outra (Dosse, 2010).

A dimensão sensorial da arte, a matéria como possibilidade de ressonâncias, a imaterialidade como seu potencial expressivo, permitem refletir sobre o texto, quer como representação ou como pré-texto ${ }^{2}$, enquanto espaço privilegiado para a diferença e, portanto, para a subjetivação.

\section{Presença e Identidade como Diferença}

$\mathrm{O}$ que é pensar sem subordinar a diferença à identidade, pergunta Roberto Machado ao introduzir recente tradução de Gilles Deleuze (2010). Repetir um 
texto, Machado argumenta, não é buscar sua identidade, mas afirmar sua diferença; é pensar em seu próprio nome usando o nome de um outro, organizar seu texto a partir de um ponto de vista, de uma perspectiva que faz o objeto estudado sofrer pequenas ou grandes torções, a fim de ser integrado às suas próprias questões. Para Deleuze, o teatro é crítico quando opera amputando, subtraindo alguma coisa, alguns dos elementos do texto original, para fazer aparecer algo diferente. Não é apenas a matéria do texto, a história original que é modificada; é também a forma de apresentá-la, que cessa de ser representação, constituindo-se como um teatro da não representação.

A presença em um teatro da não representação, na concepção de Deleuze, ao buscar sua identidade, não só afirma sua diferença como também forma ou reafirma conceitos, que vão ganhando consistência e ressoando internamente a cada repetição. Ao observar uma oficina de Jean-Pierre Ryngaert na Universidade de São Paulo/USP, em 2009, sobre o estado de jogo ou o jogo colado ao texto, ou o jogo da interpretação (me parece que qualquer das denominações dá conta do que observei), percebi a materialização desta afirmação de Deleuze (aqui resumida). Ryngaert estava trabalhando com uma pequena cena, e com dois atores por vez. Ao conduzir o jogo de cada par com o espaço e o texto, ele tornou visível a multiplicidade de significações a partir do mesmo texto. Neste caso, foi reafirmada por Ryngaert a diferença de cada interpretação e de cada condução do processo. Seria possível dizer que a presença dos atores, ao ganhar consistência, se afirmou como não representação da intenção do autor? Este jogo de interpretação poderia ser considerado, via Wolfgang Iser, como preenchimento de vazios do texto? Caso a interpretação esteja centrada em um texto ou pré-texto imagético, ou em uma sequência de ações físicas criadas a partir da interação corpo-espaço, a multiplicidade de significações indicaria um teatro da não representação? Foi o questionamento de Ryngaert, para cada dupla, que gerou significações distintas; bloqueou ações estabelecidas a priori e garantiu o estado de jogo ${ }^{3}$.

As pequenas e grandes torções que amputam e subtraem elementos do texto original fazem aparecer a 
diferença e caracterizam o jogo do texto. $\mathrm{O}$ ator/aluno ao priorizar um olhar, ao identificar o que lhe toca, está amputando outras possibilidades de leitura, eliminando tudo o que não lhe faz sentido ou não lhe é significativo. Estas pequenas ou grandes torções que o ator tece no texto, seja este escrito, imagético ou sonoro, abre espaço para a presença, o sensorial, a intensidade emocional para processos de subjetivação. A interação sensorial com o espaço, o texto e o outro, e a decorrente intensidade emocional que isto gera, vão definir a energia de sua presença em cena. Por esta perspectiva é possível perceber a identidade como diferença; pela mesma perspectiva é possível perceber a energia de um processo de subjetivação.

\section{Drama e Processos de Subjetivação}

Em que medida a associação entre texto e jogo, no âmbito da representação e da performance, permite visualizar, explorar e mediar a personificação, a observação da diversidade e a quebra de consenso? Se no processo de criação a tensão do contexto da ficção gera a energia para a investigação cênica, o jogo permite o distanciamento para perceber a relevância do material investigado. A tensão inicial é deslocada do processo para o produto - abrindo espaço para a ambiguidade, a indefinição, a incerteza.

O trabalho físico e mental de descobrir e criar conexões, ressonâncias e narrativas a partir da justaposição e reordenação do espaço/ambientação fragmentos de texto - experimentação/representação faz emergir significados abertos a múltiplos níveis de interpretação, e permite vislumbrar uma estética que privilegie as vozes (social e expressiva) dos participantes e a mobilidade da significação.

\section{Um Testemunho}

Anos atrás observei à distância, durante alguns meses, um grupo de adolescentes jogando Ultima VII, um role playing game de computador (CD). Espantava-me o número de horas que passavam, por dia, concentrados e engajados no jogo, e me questionava como nós, professores de teatro, com espaço, som, interações ao 
vivo, tínhamos dificuldade em conseguir 50 minutos de engajamento com um jogo real. Após alguns meses de observação, foi lançado o Ultima Online, um dos primeiros jogos online com múltiplos jogadores. Os adolescentes se inscreveram imediatamente (era necessário pagar uma taxa mensal), e passavam horas jogando em horários incomuns, a fim de interagir com maior número de pessoas de hemisférios distintos. Após dois ou três meses, os encontrei de volta ao Ultima VII...

Eu: Não pagaram a mensalidade?

Eles: Pagamos.

Eu: A internet está for a do ar?

Eles: Não. Tá OK.

$\mathrm{Eu}$ : Por que não estão online?

Eles: Se não há um grande jogador online, só aparece contribuição estúpida, nenhuma história interessante, nem boas falas.

Este episódio me remeteu ao impacto que tive com os processos de drama, conduzidos, a título de demonstração e formação de professores, por Dorothy Heathcote em escolas de Birmingham entre 1990 e 1994, período de meu doutorado. Este impacto não tinha apenas a ver com sua atuação como atriz ou dramaturg, mas principalmente com a quantidade e a qualidade das referências contextuais e linguísticas que ela cruzava nestes encontros teatrais. O impacto tinha a ver com o papel do professor como intelectual transformador que, segundo Henri Giroux, se caracteriza como

[...] o da libertação da memória, o reconhecimento daqueles exemplos de sofrimento público e privado cujas causas e manifestações exigem entendimento e compaixão [...] o desvelamento do horror do sofrimento passado e a dignidade e solidariedade da resistência nos alertam para as condições históricas que constroem tais experiências (1997, p. 30).

Mas, principalmente, o impacto tem a ver com a perspectiva do professor como aquele que desafia o conhecimento estabelecido. É o prazer de cruzar fronteiras em termos de conhecimento e de acessar informações que provocam a imersão no contexto ficcional. 
O contexto da ficção atua na capacidade do participante desempenhar papéis, projetando-se imaginária e fisicamente na situação; permite organizar momentaneamente a experiência em uma série de memórias e vivenciar situações não cotidianas através da história de outros. David Novitz (1997) afirma que as histórias pessoais são construídas da mesma forma que um artista cria sua arte, selecionando e ordenando experiências em um banco de memórias pessoais que se torna o significante de nossa identidade.

Engajar alunos na construção e/ou investigação de narrativas teatrais, que impliquem criação nos campos da dramaturgia, improvisação, interpretação e encenação, é um dos pressupostos do drama na educação. Como ponto de partida, o process drama (terminologia usada aqui para enfatizar o processo de construção da narrativa) arrola convenções agrupadas de acordo com ações para criação de contexto, ações para o desenvolvimento de narrativas, ações poéticas e ações reflexivas. Jonothan Neelands (1990), ao discriminar estas convenções, abre possibilidades para trabalhar as questões básicas do fazer teatral em grupos - criação de contexto e desenvolvimento de narrativas nas perspectivas poéticas e reflexivas - sem que seja necessário interromper a imersão no jogo cênico para atingir seus objetivos. Cecily O’Neill (1995) apresenta sequências de aspectos estruturais de textos clássicos, mostrando caminhos para sua atualização e apropriação. Judith Ackroyd (2004) distingue os papéis, alternativos ou cumulativos, do professor - como ator, dramaturg e/ou encenador - na coordenação de um processo de drama. John Somers, abaixo, introduz uma estratégia para a participação indireta do professor na construção coletiva de uma narrativa cênica.

\section{Um Exemplo, uma Possibilidade}

John Somers (2011), ao criar a estratégia do estímulo composto e os pressupostos teóricos que a sustentam, descritos a seguir, a apresenta através da imagem de um foguete que conduz a nave principal - a história dos participantes do drama, seus personagens e o mundo em que vivem - em voo, antes de se soltar. A 
energia e o interesse gerados pelo estímulo composto, diz ele, são cruciais para assegurar o envolvimento do participante. $\mathrm{O}$ estímulo composto provê um forte reforço inicial para a criação da narrativa em cena e, uma vez esta tenha sido iniciada, passa a servir como uma referência contínua no processo de criação.

Um artefato individual tem um potencial limitado para gerar histórias, diz Somers. A imagem de um bebê, por exemplo, torna difícil criar uma história que vá além do conceito do bebê. Se adicionado o som de um metrônomo à imagem, um novo ímpeto para a criação da história é gerado. A história geralmente não ficará centrada na imagem do bebê ou no tique-taque do metrônomo, mas será mantida no campo de força de sua interação. Documentos incluídos em um processo de drama podem ser mais sutis ou mais complexos - a formalidade de uma carta, endereçada a um personagem por um advogado, pode ser confrontada com uma nota pessoal; nesta o autor evoca visões de um relacionamento que deu errado, uma intimidade que agora é exposta para disputa legal. Como o bebê e o metrônomo, a história é para ser encontrada no cruzamento entre os documentos.

O estímulo composto é, assim, um conjunto de diferentes artefatos - objetos, fotografias, cartas e outros documentos, por exemplo, incluídos em um container, envelope, maleta, ou similar, apropriado. A significância é dada pela justaposição cuidadosa de seu conteúdo - o relacionamento entre eles e a maneira como o detalhe dos objetos sugere motivação e ação humana; uma fotografia amassada, por exemplo, sugere mais do que uma fotografia comum.

Experiências realizadas no Brasil, com a composição e introdução de estímulos em processos de drama e práticas performativas, revelam como ambos - o fazer e o receber o pacote - intensificam a intimação do imaginário, a credibilidade dos problemas enfrentados pelos personagens, introduzem informações sobre a situação em pauta ou referências sobre a cena sendo criada, acrescentam uma perspectiva crítica, para levantar questionamentos de ordem ética. Nesta perspectiva, o estímulo composto torna-se um procedimento pedagógico 
para uma intervenção indireta do professor, via introdução de material (imagens, textos e objetos).

Exemplificando, se a cena (a partir de texto, narrativa oral, jogo teatral) se referir ao desaparecimento de um misterioso ermitão, o container poderá ser uma velha valise encontrada na plataforma de uma estação de trem; caso a história envolva atos de violência por parte de um jovem, o container poderá ser uma caixa-arquivo com objetos e documentos encontrados no escaninho de seu emprego; se a história se referir a uma jovem que se suicidou, um envelope com uma página de seu diário, fotos, uma flor seca, um ticket de embarque, uma bula de remédio, um diagnóstico médico, poderão ser entregue aos alunos-pesquisadores.

O significado do conteúdo da valise, do arquivo, do envelope não poderá ser muito óbvio, nem impossível de fazer sentido - deverá estar na fronteira de possíveis interpretações. É este espaço de fronteira, entre ficção e realidade, entre possibilidades de interpretação, entre o contexto do drama e o material encontrado, que instaura um estado de jogo e o engajamento físico e emocional dos participantes. Engajamento físico porque os participantes irão apresentar o que está por trás destes objetos e mensagens, de forma convincente, como se fossem flashes do passado ou da memória de um deles. Essas reconstituições podem ocupar o tempo de algumas aulas, exigir observação, ações e atitudes externas à escola, investigação de fotografias ou cenas cinematográficas etc. São reconstituições que carregam elementos de representação, repetição e citação. Engajamento emocional porque a criação destas reconstituições envolve memórias, afetos e desafetos, identificações e projeções.

O grau e o potencial do engajamento vão depender do grau e do potencial dos objetos e documentos para sugerirem propriedade e uso. Daí a necessidade de estarem inter-relacionados: uma fotografia amassada poderá indicar o momento de separação anunciado em um bilhete; uma camisa rasgada e com sangue poderá incluir o proprietário do pacote/recipiente no acidente que vitimou um colega, ou sua intenção de usar este material no futuro para chantagear alguém. Assim, o gênero da 
cena estará relacionado com a faixa etária e o interesse dos participantes, podendo o mesmo material revelar características românticas, investigações criminais, ou cenas grotescas (camisa rasgada e com sangue já gerou cenas sobre o passado dos integrantes como internos da Fundação Estadual do Bem-estar do Menor/FEBEM, traições conjugais e ataque de vampiros).

Os documentos e os objetos, associados entre si, e relacionados com a investigação cênica em curso, quer esta tenha partido da materialidade do corpo no espaço ou da imaterialidade da carga emocional de uma informação, preenchem os vazios da representação ou da performance.

No caso de práticas performáticas, documentos e objetos ativam ações e reações que não estão necessariamente relacionadas a um objetivo comum ou a um roteiro pré-fixado. Da mesma forma, poderão levar a interações entre os participantes ou não, por exemplo: uma situação em que os atores são indivíduos em uma multidão, ou passageiros de um trem parado no meio do nada, e similares, o material recebido individualmente irá gerar ações (internas ou externas) que ajudarão a afirmar e identificar sua presença em cena.

No caso de representações, o estímulo composto pode ser introduzido a um dos personagens, a uma dupla ou grupo deles, ou ao coletivo. O motivo dependerá do objetivo da cena ou da montagem, das tensões criadas, do jogo das interações entre os personagens. A interpretação dos documentos e objetos poderá ser feita coletivamente, ou seu conteúdo ser associado a diferentes indivíduos, e cada documento ou objeto ser incorporado como parte das motivações, intenções e caracterização do ator que o recebeu.

A concepção e criação do pacote de estímulos composto leva em consideração a materialidade dos elementos introduzidos, que serão o suporte de ações ou da cena como um todo, e principalmente sua imaterialidade, ou seja, seu potencial expressivo e emocional que irá dinamizar o processo de investigação cênica.

Neste contexto se afirmam as presenças, justificadas e objetivadas pelos pontos de vista 
particulares de seus autores, protagonistas das situações criadas e apresentadas.

\section{Representação, Práticas Performativas e Presença em Cena}

Este artigo procurou ressaltar como a presença cênica, resultante de processos de subjetivação, responde aos mesmos princípios pedagógicos nos campos do teatro como representação e do teatro como prática performativa.

A experiência do ator e do aluno, como personagem ou como performer, regida pela intenção (o que quero expressar/comunicar) e pelo afeto (o prazer da expressão/ comunicação) se constitui como uma experiência subjetiva que se relaciona com a materialidade e a imaterialidade da criação.

Processos de subjetivação, gerados pela introdução de materiais que sugerem ações e geram motivações, são criados para introduzir tensão dramática e serem investigados através da ação física. Sua eficácia relaciona-se com os sentimentos despertados por sua aparente autenticidade e pela empatia que possam gerar com as questões introduzidas. Em uso, encorajam atitudes e respostas que caracterizam presença a partir de uma configuração de posição do aluno/ator. O texto, o prétexto, imagens, objetos e movimentos que levaram a esta configuração de posição foram reconstruídos e ressignificados, formando um enquadramento para o fluxo de saberes e percepções.

\footnotetext{
Notas

${ }^{1}$ Drama, process drama, drama education são denominações alternativas para o ensino do teatro na escola, correspondendo ao espaço do teatro educação no contexto do ensino brasileiro. Uso a expressão drama para me referir à metodologia específica que prioriza o contexto ficcional e o enquadramento de situações (frames) para instalar o estado de jogo e o roleplay.

2 Pré-texto refere-se ao entendimento de que um texto - social, literário, imagético, sonoro, deve figurar como pano de fundo para orientar a condução do trabalho de teatro em grupo; segundo Cecily O'Neil (1995), o pré-texto opera como uma espécie de forma-suporte para os significados sendo explorados.
} 
${ }^{3}$ À ocasião eu assisti a um encontro dos alunos com Ryngaert; esta foi minha percepção de uma manhã de trabalho; não tenho referências para entender o curso como um todo.

\section{Referências}

ACKROYD, Judith. Role Reconsidered - a re-evaluation of the relationship between teacher in role and acting. Staffordshiere: Tremtham Books Limited, 2004.

BACHELARD, Gaston. A Formação do Espírito Científico. Rio de Janeiro: Contraponto, 1996.

CABRAL, Beatriz. Looking for Change - towards breaking down habitus. Education \& Theatre Journal, Atenas, TheatroEdu, v. 10, p. 13-22, 2009.

COUCHOT, Edmond. A Tecnologia na Arte, da Fotografia à Realidade Virtual. Porto Alegre: UFRGS Editora, 2003.

DELEUZE, Gilles. Diferença e Repetição. São Paulo: Graal, 2009.

DOSSE, François. Gilles Deleuze \& Félix Guattari - Biografia Cruzada. Porto Alegre: Artmed, 2010.

GIROUX, Henri. Os Professores como Intelectuais. Porto Alegre: Artes Médicas, 1997.

ISER, Wolfgang. O Jogo do Texto. In: LIMA, Luiz Costa. A Literatura e o Leitor. São Paulo: Paz e Terra, 2002.

MACHADO, Roberto. Introdução. In: DELEUZE, Gilles. Sobre o Teatro - um manifesto de menos; o esgotado. Rio de Janeiro: Zahar, 2010.

NEELANDS, Jonothan. Structuring Drama Work. Cambridge University Press, 1990.

NOVITZ, David. Memory, Identity, Community. New York: Sunny Press, 1997.

O'NEILL, Cecily. Drama Worlds - a framework for process drama. Portsmouth: Heinemann, 1995.

PAVIS, Patrice. Dicionário do Teatro. São Paulo: Perspectiva, 2003.

RYNGAERT, Jean-Pierre. Jogar, Representar: práticas dramáticas e formação. São Paulo: Cosac Naify, 2009.

SOMERS, John. Narrativa, Drama e Estímulo Composto. Tradução de Beatriz Cabral. Urdimento - Revista de Estudos em Artes Cênicas, Florianópolis, UDESC/CEART, v. 1 , n. 17, p. 175-186, 2011.

TUAN, Yi-Fu. Space and Place - the perspective of experience. USA: University of Minnesota Press, 2008.

WOLFF, Janet. The Aesthetics of Uncertainty. Porto Alegre: Editora da UFRGS, 2008.

Beatriz Ângela Vieira Cabral, Presença e Processos de Subjetivação

R.bras.est.pres., Porto Alegre, v.1, n.1, p. 107-120, jan./jun., 2011.

Disponível em http://www.seer.ufrgs.br/presenca 
Beatriz Ângela Vieira Cabral é professora na Graduação e no Programa de PósGraduação em Teatro do Centro de Artes da Universidade do Estado de Santa Catarina e Diretora de Artes Cênicas na Universidade Federal de Santa Catarina. Mestre pela Escola de Comunicação e Artes da Universidade de São Paulo e PhD pela University of Central England/Grã-Bretanha. Bolsista de Produtividade e Pesquisa/CNPq.

E-mail: bcbiange@gmail.com

Recebido em abril de 2011. Aprovado em junho de 2011. 